\title{
Da arte de fazer ciência e de comer jabuticabas - Uma homenagem ao Prof. Dr. Ricardo Renzo Brentani
}

\section{About the art of being a scientist and eating jabuticabas - A tribute to Prof. Dr. Ricardo Renzo Brentani}

\author{
Emmanuel Dias-Neto1,2, Wagner F. Gattaz ${ }^{1}$ \\ 1 Laboratório de Neurociências Alzira Denise Hertzog Silva (LIM-27), Departamento e Instituto de Psiquiatria, Faculdade de Medicina da Universidade de São Paulo (USP) São Paulo, SP, Brasil. \\ 2 Laboratório de Genômica Médica, Centro Internacional de Pesquisa e Ensino (CIPE), Hospital A.C. Camargo, São Paulo, SP, Brasil.
}

Dias-Neto E, Gattaz WF / Rev Psiq Clín. 2012;39(1):1-4

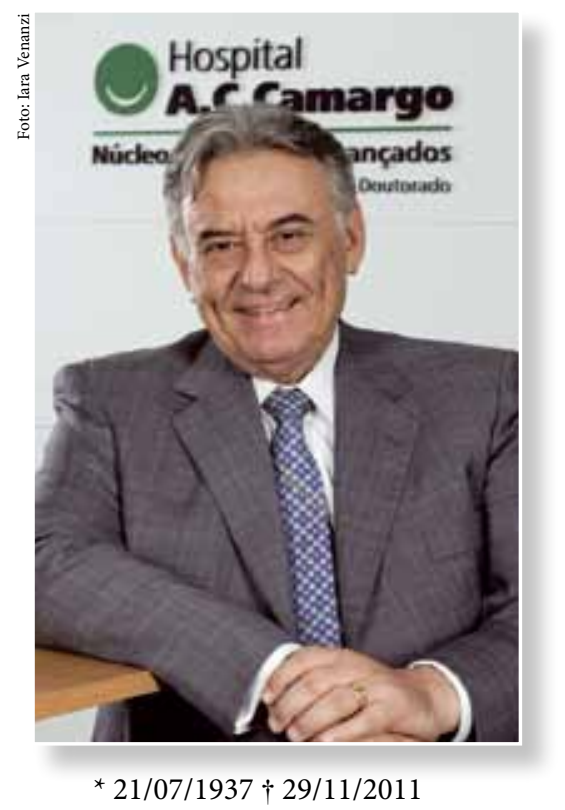

No último dia 29 de novembro de 2011, o Brasil perdeu um de seus maiores cientistas. Um infarto fulminante tirou de nossa convivência o estimado professor Ricardo Renzo Brentani. Neste artigo, buscamos fazer uma simples homenagem a esse grande homem, eminente cientista e querido amigo. Destacamos algumas etapas da sua formação, de suas atividades acadêmicas, científicas e administrativas, além de algumas poucas estórias permeadas por alguns de seus ensinamentos. Como talvez fique claro neste texto, por vezes é muito difícil - e certamente seria artificial - tentar separar o homem do cientista, ou o pesquisador do administrador. Desse modo, não tentamos forçar muito qualquer divisão formal entre esses compartimentos.

\section{Da Itália para o Brasil - o início de uma brilhante carreira científica}

Ricardo Brentani nasceu na cidade de Trieste, na Itália, em 21 de julho de 1937. Filho do casal Segismundo e Gerda Brentani, ele industrial e ela uma renomada artista plástica, mudou-se com a família para o Brasil com apenas 1 ano de idade. Cursou o secundário no Instituto Mackenzie de 1949 a 1955. Graduou-se pela Faculdade de Medicina da Universidade de São Paulo em 1962, doutorou-se em 1966 pelo Departamento de Química Fisiológica e Físico-Química da Faculdade de Medicina da Universidade de São Paulo (USP), tendo como orientador o Prof. Dr. Isaias Raw, apresentando a tese "Purificação e propriedades do RNA nucleolar de fígado de rato". Recebeu o título de livre-docente pelo Departamento de Bioquímica da USP em 1969 e o de professor titular pela Faculdade de Medicina da USP em 1980. Torcia pelo Santos e casou-se há mais de 50 anos com Maria Mitzi Brentani, química formada pela USP e companheira de estudos, sonhos e artigos, com quem teve quatro filhos.

Sua brilhante trajetória científica, interrompida abruptamente no final de 2011, teve início aos 22 anos, em 1959, com seu primeiro artigo, publicado no American Journal of Physiology, sob a tutela do professor Michel Rabinovitch. Desde o início a carreira científica de Brentani já se mostrava excepcional. Logo após concluir seu doutorado pela FMUSP, Brentani já tinha sete artigos publicados, sendo três deles na revista Nature.

Seus interesses científicos eram diversos. No início de sua carreira despontava o bioquímico desvendando o papel do nucléolo no processamento de mRNA, passando pelas propriedades de hibridização de RNA - que mais tarde o levaria a seus famosos estudos de hidropaticidade complementar. Posteriormente, avançou para a caracterização de mRNAs de colágenos, incluindo-se aí o seu artigo mais citado - 770 vezes -, no qual, em conjunto com o professor Junqueira, ele descrevia um método para coloração e detecção do colágeno, até hoje usado na rotina de diversos laboratórios.

Seus estudos posteriores envolveram ainda o papel das lamininas, culminando com um artigo na revista Science, no qual demonstrou que, graças a um receptor de laminina presente apenas nos Staphylococcus patogênicos, estes conseguem invadir, se disseminar e 
causar abcessos, em um belo paralelo com o que ocorre com células invasivas de tumores metastáticos.

Mais recentemente se interessou por neurociências, contribuindo de modo marcante para o maior conhecimento da proteína do príon, auxiliando na descoberta de seus receptores, ligantes e suas variantes em doenças humanas, incluindo a esquizofrenia (em um artigo instigante publicado com sua filha Helena Brentani na revista Nature). Ultimamente, encontrava-se ainda mais encantado com a genômica, com a capacidade de sequenciamento genômico individual e a descoberta de marcadores de agressividade tumoral desvendados com o sequenciamento do conjunto de genes expressos em diferentes tumores. Uma das vertentes que mais o entusiasmavam ultimamente era a substituição dos microarrays de cDNA pelo sequenciamento de nova geração, culminando com a disponibilização dessa tecnologia como ferramenta para medicina personalizada empregada no Hospital A.C. Camargo. Tamanho era o seu envolvimento atual com diversos projetos científicos - ainda em curso não apenas no Hospital A.C. Camargo, mas também em instituições colaboradoras incluindo o MD Anderson Cancer Center e a Harvard University - que dezenas de artigos de sua autoria ainda serão publicadas em revistas do mais alto impacto.

Sua produção científica possui pelo menos três características marcantes, que em geral estão presentes na produção dos grandes cientistas: quantidade, diversidade e qualidade. Se limitamos nossa análise apenas ao universo que compreende os artigos indexados no PubMed, vemos um total de 152 artigos e um índice $\mathrm{H}=35$ (claramente subestimado pela falha de indexação das citações mais antigas).

\section{0 administrador}

Inúmeros exemplos ilustram o seu sucesso como um administrador de raciocínio rápido, língua afiada e que sempre externava as suas opiniões, por mais polêmicas que fossem. Um de seus combates mais ferrenhos, e que mais criou desafetos, foi sua posição franca contra o excesso de escolas de medicina no Brasil - declarando-se abertamente a favor do fechamento daquelas de baixo padrão de ensino e do aumento de vagas para as boas escolas. Alertava sempre para a importância e a falta do ensino da oncologia nos cursos de medicina do país.

Em sua carreira universitária, toda ela ligada à Universidade de São Paulo, iniciou como auxiliar de ensino nos anos 1960, no Departamento de Química Fisiológica da Faculdade de Medicina. Com a reforma universitária, transferiu-se para o Departamento de Bioquímica, onde foi um dos responsáveis pela disciplina de Bioquímica. Com a reestruturação dos laboratórios de pesquisa na Faculdade de Medicina em 1974, Brentani organizou o Laboratório de Oncologia Experimental, que se transformou em um dos Laboratórios de Investigação Médica, em 1977. Em 1980, Brentani assumiu o cargo de professor titular em Oncologia do Departamento de Clínica Médica. Após alguns poucos anos, Brentani foi indicado como o primeiro diretor da filial brasileira do Ludwig Institute for Cancer Research (LICR), um dos principais institutos mundiais de pesquisa sobre o câncer, que tentou levar para a Faculdade de Medicina, sem sucesso. Com a aprovação do Departamento de Clínica Médica, Brentani iniciou as atividades do LICR nas dependências do Hospital do Câncer A.C. Camargo, mantido pela Fundação Antônio Prudente em 1983, ao mesmo tempo em que coordenava o curso de Oncologia Básica ministrado aos alunos do terceiro ano do curso médico e participava de disciplinas oferecidas pelo Departamento de Patologia. A necessidade de formar pesquisadores e docentes na área de Oncologia levou-o a organizar o primeiro curso de pós-graduação em Oncologia de nosso país, contando com docentes da faculdade de medicina e de pesquisadores do LICR, em 1989. Logo em seguida, assumiu a direção da Fundação Antonio Prudente, "por não mais que dois anos", disse Brentani, em 1990. Brentani atuou concomitantemente na faculdade de medicina e na Fundação Antônio Prudente até 2007, quando atingiu a aposentadoria compulsória na universidade. De 1997 a 2009, a Fundação Antônio Prudente foi considerada estatutariamente entidade associada à Universidade de
São Paulo, como outras instituições médicas, como o próprio Hospital das Clínicas da Faculdade de Medicina, para fins de programas de ensino e pesquisa. Dessa maneira, Brentani atuava em ambas as instituições, mantendo o seu foco, porém, no Instituto Ludwig e na Fundação Antônio Prudente.

O curso de pós-graduação em Oncologia, organizado por Brentani na Universidade de São Paulo, foi instrumental para formação de lideranças acadêmicas que hoje atuam na própria USP, no Hospital A.C. Camargo, no Hospital de Câncer de Barretos, entre outros hospitais e instituições de atenção aos pacientes com câncer. Em 1994, houve a oportunidade de fusão do grupo de docentes da Oncologia do Departamento de Clínica Médica com o grupo de docentes do então Departamento de Radiologia e Radioterapia. Com a fusão, a disciplina de Oncologia assumiu a responsabilidade de organizar o Serviço de Oncologia do Hospital das Clínicas, e o Departamento de Radiologia estabeleceu o Instituto de Radiologia, onde Brentani atuou como conselheiro. O crescimento da demanda do Serviço de Oncologia do Hospital das Clínicas fez com que Brentani e Giovanni Cerri, à frente do Instituto de Radiologia, e depois do Conselho Deliberativo do Hospital das Clínicas, reestruturassem o atendimento do paciente com câncer no sistema FMUSP/HC. Para essa reestruturação, Cerri contou com o apoio de Paulo Hoff, que assumiu a área de Oncologia Clínica, criada a partir da aposentadoria de Brentani em 2007. O sucesso da reestruturação do Serviço de Oncologia pelo Instituto de Radiologia foi coroado com a criação do Instituto do Câncer do Estado de São Paulo. Brentani acompanhava a distância a criação do novo instituto, antecipando a possibilidade de cooperação mútua entre as duas instituições às quais dedicou a maior parte de sua vida acadêmica. Nas palavras do professor Roger Chammas: "Coube-nos o privilégio, de ainda em vida, prestarmos-lhe uma honesta homenagem por sua carreira plural e pelo seu legado à pesquisa em Oncologia, na entrega do Prêmio Otávio Frias de Oliveira”. Esse prêmio, recebido na categoria "Personalidade de Destaque", é uma iniciativa do Instituto do Câncer do Estado de São Paulo (ICESP) em parceria com o Grupo Folha. Brentani era membro da Academia Brasileira de Ciências e recebeu inúmeros outros prêmios, tais como a Ordem Nacional do Mérito Científico (Grã-Cruz), o Prêmio Costa-Júnior, da Academia Nacional de Medicina, e o Prêmio Ciência e Cultura, da Fundação Conrado Wessel.

Nos anos em que fez parte do Conselho Deliberativo do HCFMUSP, Ricardo Brentani sempre manifestou seu apoio às causas da Psiquiatria e particularmente do Instituto de Psiquiatria (IPq) do HCFMUSP. Reconhecendo a relevância da nossa especialidade para a saúde da população, deu importante apoio quando o conselho decidia a verba a ser investida na tão necessária reforma e remodelação do IPq. A verba disponibilizada pelo governo do Estado era distribuída entre os institutos do $\mathrm{HC}$ respeitando as prioridades institucionais. $\mathrm{Na}$ ocasião, o IPq vinha apresentando déficit financeiro constante devido, mormente, à baixa remuneração do SUS para procedimentos psiquiátricos ${ }^{1}$. Com isso, alguns conselheiros questionavam a estratégia de investir em uma área deficitária. Brentani deu a palavra decisiva para o impasse, ressaltando que a nossa missão principal não era dar lucro, mas sim um bom atendimento à população. "Fazer o IPq dar lucro é muito fácil: basta transformar as enfermarias em serviços de diagnóstico por imagem. Mas não é isto o que queremos", disse Brentani em reunião memorável do Conselho, presidido pelo professor Irineu Tadeu Velasco, na qual se decidiu, ao final, destinar a verba de $\mathrm{R} \$ 15$ milhões para o início das obras da reforma do $\mathrm{IPq}^{2}$.

Brentani dirigiu o LICR em São Paulo por mais de 20 anos. Durante sua gestão, o LICR viveu sua fase de maior destaque nacional e internacional. Isso certamente se deu graças à sua sensibilidade em identificar e apoiar projetos estratégicos não apenas para a instituição, mas também para o país. Desse modo, a sala que ele

\footnotetext{
${ }^{1} \mathrm{O}$ IPq conseguiu reverter este déficit somente em 2011, com o empenho conjunto de todos os seus profissionais em um programa de excelência administrativa e assistencial.

2 Essa reforma foi concluída em 2006.
} 
ocupava na direção do LICR no quarto andar do prédio principal do Hospital A.C. Camargo foi testemunha de decisões estratégicas envolvendo pesquisadores e projetos diversos, incluindo o apoio aos estudos do vírus do HPV humano e do câncer de colo de útero (sob a coordenação da Dra. Luisa Lina Villa e que foram cruciais para o desenvolvimento e a validação da vacina anti-HPV); a criação de um grupo de estudos em neurociências, focado em doenças de príons (Dra. Vilma Martins); a estruturação da coordenação-geral do Projeto Genoma da Xylella fastidiosa (a cargo do Dr. Andrew Simpson); além do desenvolvimento final da tecnologia ORESTES de descoberta gênica e as coordenações-gerais e parte do financiamento do projeto genoma do câncer humano (LICR/Fapesp), que representou a segunda maior contribuição mundial para a descoberta dos genes humanos. Tal envolvimento teve um grande impacto nessas diferentes áreas e também foi fundamental na consolidação do Brasil como um dos mais importantes atores na área da genômica mundial.

Concomitante à direção da filial brasileira do LICR, Brentani ocupava também o cargo de diretor-presidente da Fundação Antonio Prudente, mantenedora do Hospital A.C. Camargo, cargo que ocupou até o dia de seu falecimento. Durante esse período o Hospital A.C. Camargo se consolidou como a principal instituição de pesquisa e tratamento de câncer no Brasil, publicando ultimamente uma média superior a 200 artigos/ano, colocando esse hospital como produtor de $60 \%$ dos artigos brasileiros em oncologia. Essa alta produtividade, fruto da competência dos profissionais recrutados sob sua supervisão, faz com que o A.C. Camargo seja hoje o único hospital privado do país que é um dos INCTs (Institutos Nacionais de Ciência e Tecnologia), o único que é um dos CEPIDs (Centro de Pesquisa, Inovação e Difusão - Fapesp) e o primeiro hospital privado brasileiro com um curso de pós-graduação (mestrado e doutorado) credenciado pelo MEC. Na semana de seu falecimento, o Hospital A.C. Camargo recebeu o prêmio SciValElsevier/Capes como o instituto de pesquisas brasileiro com maior índice de citação média por artigo publicado. Obviamente, tudo isso retorna como benefício direto aos pacientes ali atendidos, com taxas de cura elevadas, e que não devem nada àquelas vistas nos Estados Unidos ou na Europa.

Além de seu papel fundamental na administração do Hospital A.C. Camargo, Brentani foi por duas vezes consecutivas eleito presidente do conselho técnico administrativo da Fundação de Amparo à Pesquisa do Estado de São Paulo (Fapesp), cargo que ocupava até a sua morte.

\section{Saudades e jabuticabas}

Logo após sua morte, foram enviadas diversas mensagens de condolência. Seus muitos amigos estavam perplexos com a perda repentina de uma pessoa tão querida, e talvez como forma de aplacar a perda, as mensagens continham passagens e lembranças que ressaltam alguns aspectos desse querido e saudoso amigo. Com a devida permissão de seus autores, reproduzimos aqui algumas dessas mensagens.

"Uma das coisas que eu mais admirava no Brentani era sua personalidade muito forte, sempre enfocando áreas de pesquisa que ele achava e acreditava que eram interessantes, e não porque estavam na moda. Lembro-me da época que ele defendia o uso do conceito de complementaridade hidropática para encontrar ligantes e receptores proteicos usando códigos das fitas opostas do DNA. Para muitos, uma loucura, mas ele investiu e chegou a publicar papers no JBC e PNAS há mais de 20 anos e calou muita gente." (Prof. Arthur Gruber, PhD, Departamento de Parasitologia, ICB/USP)

"I am still numb from the news. He was a great friend and a kind soul. It was such a joy to talk to him and he was a force of nature. My true regret is that I could not spend more time with him and learn from his wisdom. My heart goes out to his immediate family and his larger global family of people he touched." (Prof. Raghu Kalluri, MD, PhD University of Harvard, USA)

"There was a lot of turmoil in the interplay between academia and politics between 1964-1981. By the time he graduated and doctored from USP Medical School, Dr. Brentani had already published three (!) papers in the prestigious journal Nature. However, both of his advisors at the time went into self-exile to top universities abroad (Dr. Michel Rabinovitch to Paris and New York; Dr. Isaias Raw to Jerusalem, Cambridge, and New York). He spent the next five decades directing basic science research at USP, Ludwig Institute for Cancer Research, A.C. Camargo Hospital, and Fapesp. Aside from his heavy administrative duties, Professor Brentani had quite a productives cientific career: he has published over 150 peer-reviewed publications mostly in respected international journals. Most impressive and rare to find: his areas of research interest were wide ranging and included extremely different and complex areas such as cell adhesion, tumor metastasis, extracellular matrix, protein complementary hydropathy, prion-related diseases (mad-cow disease), and cancer genomics. Professor Brentani was a true visionary with a privileged intellect and the highest sense of honor and duty. He has never loss his joy at the discovery process. At a more personal level, Renata and I will miss him dearly at many levels including his mentor ship, insight ful friend ship, sense of humor and wit. In sum, professor Brentani was truly an one-of-a-kind original act that will be very hard for anyone to follow." (Prof. Wadih Arap, MD, PhD - University of Texas, MD Anderson Cancer Center, USA)

"For me it is not often in one's academic career to meet a role model who has changed our way of thinking in cancer research. Some of these noted scientists include: Dr. Mina Bissell, who changed our way of thinking in regards to the tumor microenvironment's role in cancer, Dr. Judah Folkman who initiated the entire field of angiogenesis and Dr. Josh Fidler, who has made enormous contributions in cancer metastasis. Dr. Ricardo Brentani, belong son this list of eminent scientists who have changed our way of thinking 'out of the box' for certain monumental discoveries. Dr. Brentani has made novel discoveries in understanding the mechanisms in prion biology. $\mathrm{He}$ has also made significant contributions in cancer genetics. Similar to the great noted scientists above, Dr. Brentani, treated all individuals with enormous respect. He was always willing to hear what you had to say and he was sure to give you his 'straight up' opinion (whether he agreed or disagreed with what you said) but heat least respected people for their thoughts and ideas. What I admired the most about him is his $100 \%$ support of the careers of young physicians and scientists. Because of him, I am a collaborator of one of his former postdocs, Dr. Vilma Martins, who is now a very successful scientist in her own right and because of both of them, I now have a gifted postdoc, Dr. Bruno Costa da Silva, from Brazil in my own lab. I feel bringing the Ludwig Institute to South America and making the Camargo Hospital a successful cancer hospital, for both patient care and research, on the level of Memorial Sloan-Kettering Cancer Center or MD Anderson Cancer Center, his legacy will live forever. He was way ahead of his time and really served Brazil with 'a first' by there cognition he brought in medical research even before all the 'other firsts' to happen in your country (i.e. the World Cup, the Olympics). Importantly, he was full of life, full of laughter and full of fun. He was so stimulating all around." (Prof. David Lyden, MD, PhD - Weill Cornell Medical College, USA)

"I will remember professor Ricardo Brentani as an excellent scientist and a strong and visionary leader for a very successful Branch of the Ludwig Institute for Cancer Research in Sao Paulo, but also as a colorful and warm person who cared a lot for the people around him. I have very fond memories from our many meetings, and remember in particular Ricardo's sharp and humoristic comments on almost any kind of subject. I will miss Ricardo very much." (Prof. Carl-Henrik Heldin, MD, PhD, Director of the Ludwig Institute for Cancer Research Ltd, Uppsala University, Uppsala, Sweden)

"I first met Dr. Brentani in September, 2009, which I visited the Champalimaud Center in Lisbon. Since then, we met several times in scientific meetings in Lisbon, New York and Sao Paulo. My conversations with Dr. Brentani have always been very enjoyable and highly stimulating. He had such a keen mind and genuine interest in knowing my research in cancer metastasis, and here ally cared about the success of the next generation of young scientists. In my mind, 
Dr. Brentani represents the best of Brazilian science. His integrity, intelligence, warm-heartedness, contagious optimism and his great leadership all left a lasting impression on me. I am tremendously saddened to lost such a great friend and colleague, but we will forever remember his legacy." (Prof. Yibin Kang, PhD - Department of Molecular Biology, Princeton University, USA)

É interessante notar que os adjetivos mais comumente usados por esses amigos, para ressaltar as características mais marcantes do Dr. Brentani, incluíam sua forte personalidade, sabedoria, produtividade e abrangência de sua produção científica, além de seu grande senso de humor e bom coração.

Como diretor do LICR ou do Hospital A.C. Camargo, ele sempre insistia que a "boa ciência" teria seu apoio incondicional. Não importava se o alvo da investigação era uma bactéria que causava doenças em plantas, um parasita, a "doença da vaca louca" ou mesmo a descoberta de genes ativos no câncer. Desse modo, sob sua gestão, o hospital contratou físicos, matemáticos e até mesmo agrônomos para o seu corpo de pesquisadores.

Suas últimas ações à frente do Hospital A.C. Camargo incluíram a construção de um moderno e amplo centro de pesquisas (denominado Centro Internacional de Pesquisa e Ensino, ou CIPE) e a assinatura de um convênio de US\$ 10 milhões com a empresa Cardinal Health, para instalação de um cíclotron e a produção de radiofármacos a serem usados na clínica e na pesquisa. Já pensando na continuidade das pesquisas no hospital, ele havia recentemente contratado o Prof. Dr. Pierre Hainaut (que anteriormente era pesquisador da International
Agency for Cancer Research, em Lyon, França) para assumir o cargo de diretor científico do CIPE. Dr. Hainaut assumirá suas funções ainda no mês de janeiro de 2012 e vai garantir que o Hospital A.C. Camargo permaneça com uma posição de destaque nacional e internacional.

Brentani gostava de dizer que "fazer ciência é como chupar jabuticabas. Você vê aquela árvore linda, cheia de frutos deliciosos, e quer comer todos. Mas é impossível. Temos que escolher apenas os melhores". Essa frase pode parecer contraditória com a diversidade e a abrangência de sua contribuição científica. No entanto, o que importava sempre era dar espaço e oportunidade para uma ciência investigativa de qualidade, pois esta sempre abre portas e oportunidades. Essas eram as melhores "jabuticabas". Por tudo que Brentani fez fica claro que os frutos da sua jabuticabeira foram bem escolhidos, aproveitados da melhor maneira possível e vão gerar novas jabuticabeiras que certamente frutificarão com o apoio dos inúmeros pesquisadores brasileiros que com ele tiveram a sorte de conviver.

\section{Agradecimentos}

Os autores agradecem pelas informações e pelo texto gentilmente redigido pelo Prof. Dr. Roger Chammas e são gratos aos Drs. Arthur Gruber, Wadih Arap, Yibin Kang, Roger Chammas, David Lyden, Raghu Kalluri e Carl-Henrik Heldin pelo envio e autorização de publicação de seus depoimentos. Os autores também agradecem pelo apoio contínuo recebido pelo LIM-27 da Associação Beneficente Alzira Denise Hertzog Silva (ABADHS). 